\title{
Cooling of the mesosphere and lower thermosphere due to doubling of $\mathrm{CO}_{2}$
}

\author{
R. A. Akmaev' ${ }^{1}$, V. I. Fomichev ${ }^{2}$ \\ ${ }^{1}$ Department of Aerospace Engineering Sciences, Campus Box 429, University of Colorado, Boulder, CO 80309-0429, USA \\ 2 Department of Earth and Atmospheric Science, York University, 4700 Keele Street, North York, Ontario M3J 1P3, Canada
}

Received: 28 July 1997 / Revised: 2 March 1998 / Accepted: 3 March 1998

\begin{abstract}
A new parameterization of infrared radiative transfer in the $15-\mu \mathrm{m} \mathrm{CO}_{2}$ band has been incorporated into the Spectral mesosphere/lower thermosphere model (SMLTM). The parameterization is applicable to calculations of heating rates above approximately $15 \mathrm{~km}$ for arbitrary vertical profiles of the $\mathrm{CO}_{2}$ concentration corresponding to the surface mixing ratio in the range 150-720 ppm. The sensitivity of the mesosphere and lower thermosphere (MLT) to doubling of $\mathrm{CO}_{2}$ has been studied. The thermal response in the MLT is mostly negative (cooling) and much stronger than in the lower atmosphere. An average cooling at the stratopause is about $14 \mathrm{~K}$. It gradually decreases to approximately $8 \mathrm{~K}$ in the upper mesosphere and again increases to about $40-50 \mathrm{~K}$ in the thermosphere. The cooling and associated thermal shrinking result in a substantial density reduction in the MLT that reaches $40-45 \%$ in the thermosphere. Various radiative, chemical, and dynamical feedbacks potentially important for the thermal response in the MLT are discussed. It is noted that the results of simulations are strikingly similar to observations of long-term trends in the MLT. This suggests that during the last 3-4 decades the thermal structure in the real upper atmosphere has undergone substantial changes driven by forcing comparable with that due to doubling of $\mathrm{CO}_{2}$.
\end{abstract}

Key words. Meteorology and atmospheric dynamics (Climatology, Middle atmosphere dynamics,

Thermospheric dynamics)

\footnotetext{
*On leave from Atmospheric Physics Department, Institute of Physics, University of St. Petersburg, Russia

Correspondence to: R. A. Akmaev (akmaev@spb.colorado.edu)
}

\section{Introduction and overview}

Contrary to relatively moderate anthropogenic temperature changes that may be expected in the lower atmosphere according to observations and model estimates, available publications predict quite dramatic thermal response to changes in optical tracer abundances in the middle and upper atmosphere. For example, with doubled $\mathrm{CO}_{2}$ concentration, an average cooling of 10-15 K can be expected in the upper stratosphere and mesosphere (approximately 50-90 km), whereas the thermospheric (above $90 \mathrm{~km}$ ) temperatures can be reduced by $40-60 \mathrm{~K}$. This severe cooling can potentially lead to substantial changes in the structure and composition of the upper atmosphere. It appears however that the problem of global change in the upper atmosphere has received disproportionately little attention. Only a few modeling studies have been performed to date and their results are sometimes inconclusive. The purpose of this work is to present quantitative estimates of the thermal response to doubling of $\mathrm{CO}_{2}$ in the mesosphere and lower thermosphere (MLT) using the three-dimensional Spectral mesosphere/lower thermosphere model (SMLTM).

A growing number of observational studies indicate negative temperature trends in the MLT during the last decades. Long-term observations made by ground-based lidars, radiosondes, rockets, and satellite-based instruments demonstrate that atmospheric temperatures decrease at a rate of about $2-3.5 \mathrm{~K} \mathrm{decade}^{-1}$ at the stratopause and in the lower mesosphere at $46-55 \mathrm{~km}$ (Aikin et al., 1991; Angell, 1991). Hauchecorne et al. (1991) analyzed temperature measurements from two mid-latitude lidars extending higher into the mesosphere during 1978-1989. They found a cooling trend of up to $4 \mathrm{~K} \mathrm{decade}^{-1}$ at $60-70 \mathrm{~km}$. Kokin and Lysenko (1994) presented results of more than 7000 rocket and radiosonde soundings obtained from five stations including two high-latitude stations, two stations at midlatitudes, 
and one station in the equatorial region over more than 25 years. They found negative temperature trends above $25 \mathrm{~km}$ with a minimum at $45 \mathrm{~km}$. The altitude dependence of the trend varied with latitude but generally the cooling trend was about $5-10 \mathrm{~K} \mathrm{decade}^{-1}$ at $60-70 \mathrm{~km}$.

There are no direct measurements of temperature trends in the upper mesosphere and lower thermosphere. From the increased frequency of occurrence of noctilucent clouds, Gadsden (1990) concluded that the average mesopause temperature in summer had decreased by about $6.4 \mathrm{~K}$ during the period 1964-1982, or at a rate of $2.5 \mathrm{~K} \mathrm{decade}^{-1}$. Golitsyn et al. (1996) combined the rocket data of Kokin and Lysenko (1994) with longterm (about 4 decades) temperature estimates from observations of emissions of hydroxyl (centered at about $87 \mathrm{~km}$ ) and the green line of atomic oxygen (about $97 \mathrm{~km}$ ) at middle latitudes. The hydroxyl emission observations suggested a negative trend of about $7 \mathrm{~K} \mathrm{decade}^{-1}$ in agreement with the rocket measurements at midlatitudes. No statistically significant trend was found in the lower thermosphere from the green-line emission. Semenov (1996) supplemented the hydroxyl and green line emission estimates with long-term observations of the red-line emission of atomic oxygen at $630 \mathrm{~nm}$ (about $270 \mathrm{~km}$ ). According to this work, during the last 40 years the maximum cooling in the middle atmosphere occurred just above $80 \mathrm{~km}$ at a rate of about $7 \mathrm{~K} \mathrm{decade}^{-1}$. There was no noticeable cooling trend registered around $100 \mathrm{~km}$. Higher in the thermosphere, however, the estimated cooling rate reached about $30 \mathrm{~K} \mathrm{decade}^{-1}$ at the heights of the red-line emission layer.

Several studies presented indirect estimates based on long-term trends of the heights of various ionospheric and emission layers. These, typically downward, trends could be associated with thermal contraction due to cooling of the underlying atmosphere (e.g., Rishbeth, 1990). Taubenheim et al. (1990) analyzed the reflection heights of low-frequency radio waves in mid-latitude summer that are closely associated with the isobaric level of $0.0052 \mathrm{mb}$ (about $80 \mathrm{~km}$ ). They found a statistically significant downward trend of the height of this level from 1962 through 1987 corresponding to a pressure reduction of about $10 \%$ at $80 \mathrm{~km}$ over the 25 year period. They estimated that this downward trend would be consistent with a uniform cooling of the mesosphere above $50 \mathrm{~km}$ by $4 \mathrm{~K}$, or at a rate of about $1.5 \mathrm{~K} \mathrm{decade}^{-1}$. Clemesha et al. (1992) also reported that the centroid height of the sodium layer in the upper mesosphere had descended by about $700 \mathrm{~m}$ between 1972 and 1987. Using the same simplified assumption of a uniform temperature change above $50 \mathrm{~km}$, they found that a cooling by $5 \mathrm{~K}$ during this period or about $3 \mathrm{~K} \mathrm{decade}^{-1}$ would be necessary. This is about twice the estimate presented by Taubenheim et al (1990). Note, however, that while Taubenheim et al. (1990) considered a pressure level at about $80 \mathrm{~km}$, the height of sodium layer in the work by Clemesha et al. (1992) centered around $92 \mathrm{~km}$. The higher estimate of a uniform temperature trend by Clemesha et al. (1992) is qualitatively consistent with the results of Kokin and
Lysenko (1994), Golitsyn et al. (1996), and Semenov (1996) suggesting that the negative temperature trend maximizes above $80 \mathrm{~km}$. In the thermosphere the data are generally more contradictory. From analysis of more than 30 years of measurements of the peak height of the ionospheric F2-layer (approximately $250-350 \mathrm{~km}$ ), the average downward trend varies from $2.4 \mathrm{~km} \mathrm{decade}^{-1}$ at mid-latitudes to $3.9 \mathrm{~km} \mathrm{decade}^{-1}$ at high latitudes according to Bremer (1992) and Ulich and Turunen (1997), respectively. Semenov (1996) estimated the descent rate of the red-line emission layer at about $10 \mathrm{~km} \mathrm{decade}^{-1}$.

Although these observational estimates differ by about a factor of 2 in the mesosphere and even more in the thermosphere, they consistently provide evidence for a real global change, possibly of anthropogenic nature, on a much bigger scale compared to that observed in the lower atmosphere. In particular, in the MLT region, all observations indicate strong cooling trends. This motivates modeling work with the aim to explain the mechanisms of currently observed trends and predict possible future changes. However, there are only a few publications on modeling of global change in the upper atmosphere. To some extent this is due to a limited availability of numerical models and adequate parameterizations of radiative transfer applicable to arbitrary mixing ratios of optically active "greenhouse" atmospheric tracers. Some important information related to radiative transfer in the upper atmosphere has only recently become available. As is the case with the observations, modeling results are often inconclusive and even contradictory in some instances.

Fels et al. (1980) first employed a three-dimensional general circulation model (GCM) in a study of sensitivity of the upper atmosphere to perturbations in ozone and carbon dioxide. They investigated the radiative and dynamical response of the atmosphere to a uniform $50 \%$ reduction of $\mathrm{O}_{3}$ and a uniform doubling of $\mathrm{CO}_{2}$. Special attention was paid to incorporation in a parametrized form of feedbacks due to ozone photochemistry in the stratosphere. With doubled $\mathrm{CO}_{2}$, they predicted an average cooling of up to $11 \mathrm{~K}$ at the stratopause gradually reducing to about $8 \mathrm{~K}$ in the mesosphere. Although the GCM had an upper boundary at about $80 \mathrm{~km}$, the simulations in the mesosphere should be considered with caution as the model did not account for small-scale gravity waves (GWs) that are currently believed to play a crucial role in the dynamics and thermal structure in the mesosphere. A similar study of the $2 \times \mathrm{CO}_{2}$ climate was conducted by Rind et al. (1990) using a GCM without chemical feedbacks.

Roble and Dickinson (1989) used a one-dimensional radiative-photochemical model to study sensitivity to doubling of $\mathrm{CO}_{2}$ and $\mathrm{CH}_{4}$ in the mesosphere and thermosphere $(\sim 60-500 \mathrm{~km})$. They predicted a global average cooling by about $10-15 \mathrm{~K}$ in the mesosphere and up to $50 \mathrm{~K}$ in the thermosphere. Due to thermal compression in an atmosphere with hydrostatic balance this cooling resulted in a reduction of atmospheric density by more than $40 \%$ at a given height in the thermosphere. The density decrease was accompanied 
by substantial changes in chemical composition. In particular, the concentration of NO was reduced by up to $50 \%$ in the lower thermosphere. Later Rishbeth and Roble (1992) generally confirmed the findings for the thermosphere using a three-dimensional GCM with chemistry. The lower boundary of this model was placed at about $95 \mathrm{~km}$, so that the results were only applicable in the thermosphere above approximately $120 \mathrm{~km}$. It should be noted that both studies used a relatively low value, compared to recent data (e.g., Shved et al., 1991, 1998), of the quenching rate coefficient, $k_{\mathrm{O}}$, for collisions of atomic oxygen and carbon dioxide that are important for radiative transfer in the $15-\mu \mathrm{m}$ band of $\mathrm{CO}_{2}$ in the region of breakdown of local thermodynamic equilibrium (LTE) approximately above $70 \mathrm{~km}$.

Berger and Dameris (1993) studied the effects of $\mathrm{CO}_{2}$ doubling with a three-dimensional mechanistic model extending from the surface to $150 \mathrm{~km}$. The model incorporated a realistic GW parameterization based on the formulation by Lindzen (1981). They predicted a maximum cooling of about $40 \mathrm{~K}$ at $105-110 \mathrm{~km}$ that reduced to about $1-2 \mathrm{~K}$ near the upper boundary. This does not quite agree with the results of Roble and Dickinson (1989) and Rishbeth and Roble (1992) according to which the cooling is of the order of $10 \mathrm{~K}$ in the upper mesosphere and should grow with height to about $40-50 \mathrm{~K}$. The study by Berger and Dameris (1993) also used a low value for $k_{\mathrm{O}}$.

Portmann et al. (1995) used a two-dimensional model with full chemistry extending up to $110 \mathrm{~km}$. They demonstrated the importance of dynamical feedbacks by GW momentum deposition in the mesosphere. They found that as a result of these feedbacks the middle atmosphere would cool due to increased $\mathrm{CO}_{2}$ even in the regions with a positive radiative forcing. They predicted cooling above $100 \mathrm{~km}$ at about half the rate reported by Berger and Dameris (1993).

In the mesosphere, the absolute differences in model predictions are not as dramatic as in the thermosphere. This is perhaps due to the fact that the direct effect of doubling of $\mathrm{CO}_{2}$ concentration is generally weaker here. Cooling to space becomes less dominant as the optical thickness of the atmosphere increases until the effect reverses to heating in the lower atmosphere (e.g., Fels et al., 1980). However, the differences in model predictions still remain noticeable. Only in some cases can they be attributed to certain deficiencies of particular models. All models predict an average cooling of about 10-15 K at the stratopause. Fels et al. (1980) stressed the importance of feedbacks due to ozone chemistry in damping the thermal response in the stratosphere. Lower temperatures lead to increase in ozone production and, consequently, in solar heating. Fels et al. (1980) used a crude parameterization of the effect based on numerical experiments with a one-dimensional radiative-chemical model. Some later studies (e.g., Portmann et al., 1995) incorporated detailed chemistry. Generally, models that account for this effect predict slightly smaller temperature changes $(10-12 \mathrm{~K})$ compared to models without chemical feedbacks (e.g., Berger and Dameris, 1993) that tend to overestimate the effect (14-
$15 \mathrm{~K})$ at the stratopause and in the lower mesosphere. Rind et al. (1990), however, also obtained an average cooling of only about $10-11 \mathrm{~K}$ at the stratopause in their GCM simulations with no chemical feedbacks.

In the upper mesosphere $(70-90 \mathrm{~km})$ the simulations by Fels et al. (1980), Berger and Dameris (1993), and Portmann et al. (1995) predicted cooling by about 8 $10 \mathrm{~K}$. Rind et al. (1990) obtained a generally smaller cooling in the upper mesosphere with some regions of heating at high latitudes in summer. Portmann et al. (1995) noted that in their simulations a temperature increase at the summer mesopause was only possible without dynamical feedbacks due to more intensive breaking of gravity waves in an atmosphere with doubled $\mathrm{CO}_{2}$. This directly contradicts the results of Rind et al. (1990) whose model incorporated a GW scheme with higher GW intensity in the atmosphere with doubled $\mathrm{CO}_{2}$. These differences can perhaps be attributed to the upper-boundary (about $85 \mathrm{~km}$ ) effects in the work of Rind et al. (1990) and the differences in specifications of GW sources in the lower atmosphere (both studies used similar GW parameterizations based on the scheme by Lindzen, 1981).

Rind et al. (1990) also reported an overall increase of the eddy energy in the middle atmosphere due to both planetary and gravity waves. This was attributed to a reduction of the gross atmospheric stability due to a relative warming in the troposphere and a cooling in the middle atmosphere. The vertical destabilization affects propagation of planetary and gravity waves through the middle atmosphere. It also favors stronger planetary and gravity wave generation in the lower atmosphere at least within the parameterization of GW sources employed in this work. The combined effect of these changes is a stronger momentum deposition by waves and a stronger residual circulation in the middle atmosphere. The enhanced circulation produces a relative warming of the polar winter stratopause. A similar effect in the upper stratosphere was detected in an earlier work by Boville (1986) in GCM simulations without a GW parameterization. It appears that this effect deserves further investigation, in particular, as to how realistic the enhanced GW generation is in a troposphere with doubled $\mathrm{CO}_{2}$. It should be noted that the effect of destabilization could be overestimated due to possible overestimation of the thermal response at the surface (about $4.2 \mathrm{~K}$ ) in the experiments of Rind et al. (1990). $2 \times \mathrm{CO}_{2}$ experiments using GCMs with interactive oceans predict an increase of the surface temperature in the range of only 1.3 to $2.3 \mathrm{~K}$ (e.g., Gates et al., 1992). Also, the enhanced residual circulation could not account for a relatively weak global average cooling at the stratopause. For quasi-stationary conditions there must be no significant global average heating effect at the stratopause due to residual circulation. One possible explanation of this relatively weak cooling is underestimation of the radiative forcing due to doubling of $\mathrm{CO}_{2}$ by Rind et al. (1990).

This brief discussion clearly demonstrates the still remaining uncertainties in model estimates of the atmospheric response to perturbations in greenhouse 
gases, in particular in the MLT region. At present there exists no ideal model that could adequately describe all complicated radiative, chemical, and dynamical interactions and feedbacks in an atmosphere with perturbed composition. It appears however that comparison of simulations performed with different models could elucidate the role of various mechanisms of global change in the upper atmosphere.

\section{Model}

The SMLTM is an extended version of the threedimensional middle atmospheric $(\sim 15-120 \mathrm{~km})$ model originally developed and described by Akmaev et al. (1992). The model has been used for simulations and diagnostics of the zonal mean climatology (Akmaev, 1994, 1997). Recently the model has been employed in diurnal-cycle simulations. To prevent spurious reflections of strong tidal waves from the upper boundary, the model has been extended into the thermosphere (Akmaev et al., 1996, 1997). The present version has the same horizontal resolution (T13) as the middle atmospheric version approximately corresponding to $9^{\circ} \times 9^{\circ}$ in latitude-longitude. The model vertical domain is divided into 38 layers of $1 / 2$ pressure scale height each and extends from the lower boundary at $100 \mathrm{mb}$ to the upper boundary at about $220 \mathrm{~km}$. Tropospheric tidal forcing is introduced via the lower boundary condition. Diurnal and semidiurnal variations of horizontal wind components, temperature, and geopotential at $100 \mathrm{mb}$ (nominal altitude $16.3 \mathrm{~km}$ ) are specified as functions of latitude and local time according to simulations with the Global-scale wave model (GSWM) (Hagan et al., 1995). The GSWM simulations are available for January, April, July and October representing the four seasons. In this study, simulations for the Northern Hemisphere winter and spring conditions (January and April) are presented.

A variety of physical processes important in the middle and upper atmosphere are represented in the model. It incorporates parametrizations of solar heating due to absorption of ultraviolet radiation by $\mathrm{O}_{2}$ and $\mathrm{O}_{3}$ and extreme ultraviolet radiation (EUV) by $\mathrm{O}, \mathrm{O}_{2}$, and $\mathrm{N}_{2}$. In the present configuration of the model, the efficiency of solar heating is specified to account both for additional heating due to exothermic reactions and for possible radiative losses in the MLT (Fomichev and Shved, 1988; Mlynczak and Solomon, 1993; Roble, 1995). This means that although the model reproduces the net solar heating well for standard conditions, it may underestimate the feedbacks due to temperature-sensitive reactions or emissions in cases where the background temperatures change substantially.

The infrared radiation transfer in the $9.6-\mu \mathrm{m} \mathrm{O}_{3}$ band is treated according to Fomichev and Shved (1985). In this study, a new parameterization of the $15-\mu \mathrm{m} \mathrm{CO}_{2}$ band (Fomichev et al., 1998) has been implemented (see also next section). The model accounts for molecular viscosity and thermal conductivity and ion drag. A discrete-spectrum gravity wave parameterization based on the formulation by Gavrilov (1990) was implemented and described in some detail by Akmaev et al. (1992) and Akmaev (1994). Modifications related to an interactive calculation of eddy diffusivity and specifications of latitudinal and seasonal variations of the gravity forcing in the lower atmosphere were introduced by Akmaev et al. (1997). The model has been found to realistically reproduce both the zonal mean circulation and strong diurnal tides and their seasonal variations in the MLT. Further details of the model implementation can be found in the papers by Akmaev (1994) and Akmaev et al. (1992, 1996, 1997).

A series of numerical experiments have been conducted in both two- and three-dimensional model configurations to assess the effects of planetary-scale motions (tides) in the MLT. In these experiments, the solar EUV fluxes and composition in the thermosphere have been specified for a moderate level of solar activity, $F_{10.7}=150 \times 10^{-22} \mathrm{~W} \mathrm{~cm}^{-2} \mathrm{~Hz}^{-1}$, according to the models by Tobiska (1991) and Hedin (1991), respectively. The model has been run for perpetual January and April conditions with a horizontally uniform vertical profile of the $\mathrm{CO}_{2}$ volume mixing ratio, $c_{\mathrm{CO}_{2}}$. The control experiments correspond to the present-day surface value of $c_{\mathrm{CO}_{2}}=360 \mathrm{ppm}$ (e.g., Kane and de Paula, 1996). For $2 \times \mathrm{CO}_{2}$ experiments, $c_{\mathrm{CO}_{2}}$ has been uniformly doubled at every pressure level. The characteristic times are relatively short in the thermosphere. It has been found however that to obtain satisfactory convergence in the mesosphere, the model should be run for at least one year from the initial conditions specified according to the MSISE-90 empirical model (Hedin, 1991).

Although the model has been demonstrated to realistically reproduce the present-day climatology in the MLT, one must realize the limitations of the current model configuration, in particular for simulations with perturbed abundances of radiatively-active tracers. The results presented here should be considered first crude estimates. The model does not include an interactive composition and cannot account for chemical feedbacks that are particularly important in the stratosphere (e.g., Fels et al., 1980). Chemical feedbacks may also be potentially important in the upper mesosphere due to temperature-dependent rates of exothermic chemical reactions (e.g., Riese et al., 1994). However, as noted earlier, the simulations by Berger and Dameris (1993) without a chemical scheme agree reasonably well in the upper mesosphere with those by Portmann et al. (1995) whose model included full interactive chemistry suggesting that the effect is not very strong. Radiative cooling in the 5.3- $\mu \mathrm{m}$ band of NO that peaks at about $140-150 \mathrm{~km}$ (Kockarts, 1980) is not explicitly calculated in the present configuration. Although the radiative loss of energy is accounted for via the solar EUV heating efficiency (Roble, 1995), the model may underestimate feedbacks in the lower thermosphere due to dependence of the NO cooling rate on temperature. As any other upper-atmospheric model without an interactive troposphere (e.g., Roble and Dickinson, 1989; Rishbeth and Roble, 1992; Berger and Dameris, 1993; Portmann et al., 1995), the SMLTM cannot self-consistently reproduce 
the effect of stronger wave generation in the lower atmosphere (Rind et al., 1990). It is able however to simulate the influence on wave propagation of changed background conditions in the middle atmosphere.

\section{Radiative forcing and feedbacks}

In this study, a new parameterization of radiative transfer in the 15- $\mu \mathrm{m} \mathrm{CO}_{2}$ band (Fomichev et al., 1998) has been implemented into the SMLTM. Essentially, it is based on a matrix formulation similar to that used by Fomichev et al. (1993) with some modifications and is applicable for heating rate calculations above approximately $15 \mathrm{~km}$. The scheme parameters can now be calculated for an arbitrary vertical profile of $c_{\mathrm{CO}_{2}}$ with the surface mixing ratio in the range $150-720 \mathrm{ppm}$. The basic profile of $c_{\mathrm{CO}_{2}}$ below approximately $120 \mathrm{~km}$ has been adopted from the work of Fomichev et al. (1998). Above that level, diffusive equilibrium for $\mathrm{CO}_{2}$ has been assumed. For non-LTE calculations, the exchange rates for collisions of $\mathrm{CO}_{2}$ with $\mathrm{N}_{2}, \mathrm{O}_{2}$, and $\mathrm{O}$ have been specified following the recommendations of Shved et al. (1998). In particular, for collisions with O, $k_{\mathrm{O}}=3 \times 10^{-12} \mathrm{~cm}^{3} \mathrm{~s}^{-1}$ which is twice the value measured by Shved et al. (1991) at room temperatures. Akmaev and Fomichev (1992) developed a matrix transformation method for efficient incorporation of radiative matrix schemes into models with arbitrary vertical coordinate grids. The method requires specification of some reference vertical temperature profile. Since it is not obvious how to specify the reference profile for $2 \times \mathrm{CO}_{2}$ experiments, spline interpolation has been used for forward interpolation of temperature to the parameterization grid and backward interpolation of heating rates to the model grid. The spline coefficients can be precalculated off-line and the whole scheme remains computationally efficient. For a full description of the new parameterization, its validation, and input information the reader is referred to the paper by Fomichev et al. (1998).

To mimic the "greenhouse effect" in the lower atmosphere (e.g., Fels et al., 1980; Rind et al., 1990; Gates et al., 1992), the surface temperature used in infrared radiation calculations has been increased by $4 \mathrm{~K}$ in experiments with doubled $\mathrm{CO}_{2}$. Likewise, the temperature at the lower boundary $(100 \mathrm{mb})$ has been increased by $1 \mathrm{~K}$. Numerical experiments have shown that the effect of these boundary conditions on the temperature distribution becomes negligible (less than $0.1 \mathrm{~K}$ ) above approximately $40 \mathrm{~km}$.

Figures 1 and 2 present heating rates in the $15-\mu \mathrm{m}$ $\mathrm{CO}_{2}$ band in the standard MSISE-90 atmosphere with the standard vertical profile of $c_{\mathrm{CO}_{2}}$. Figures 3 and 4 present the initial radiative forcing due to doubling of $\mathrm{CO}_{2}$ amount in a standard atmosphere. The heating rates and radiative forcing are generally in reasonable agreement with other studies (e.g., Fels et al., 1980; Berger and Dameris, 1993). Note, however, that in the latter study total infrared cooling rates due to all radiative tracers are presented in their Fig. 6. Also, our

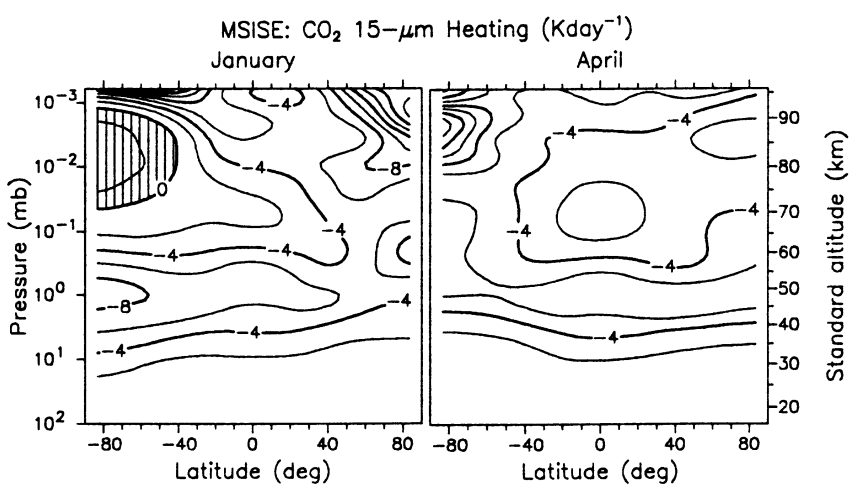

Fig. 1. $15-\mu \mathrm{m} \mathrm{CO}_{2}$ band heating rates below about $95 \mathrm{~km}$ for standard conditions in January and April (positive area shaded, contour interval $2 \mathrm{~K} \mathrm{day}^{-1}$ )

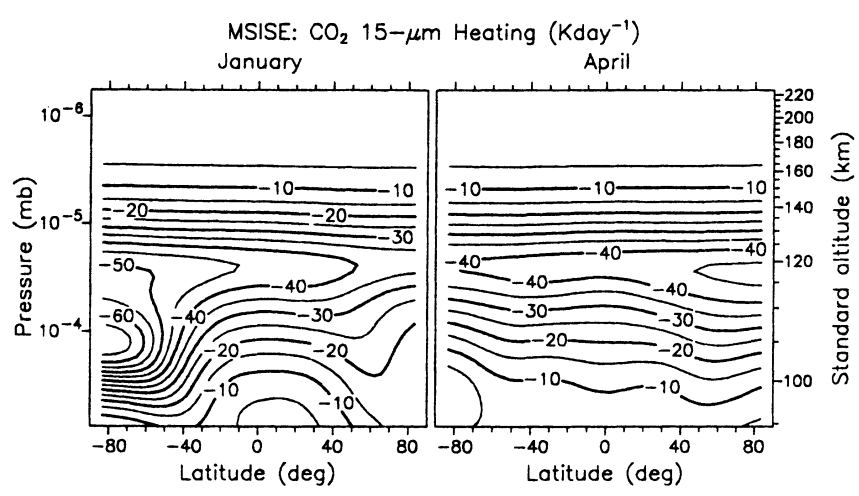

Fig. 2. Same as in Fig. 1 but above $95 \mathrm{~km}$ (contour interval $5 \mathrm{~K} \mathrm{day}^{-1}$ )

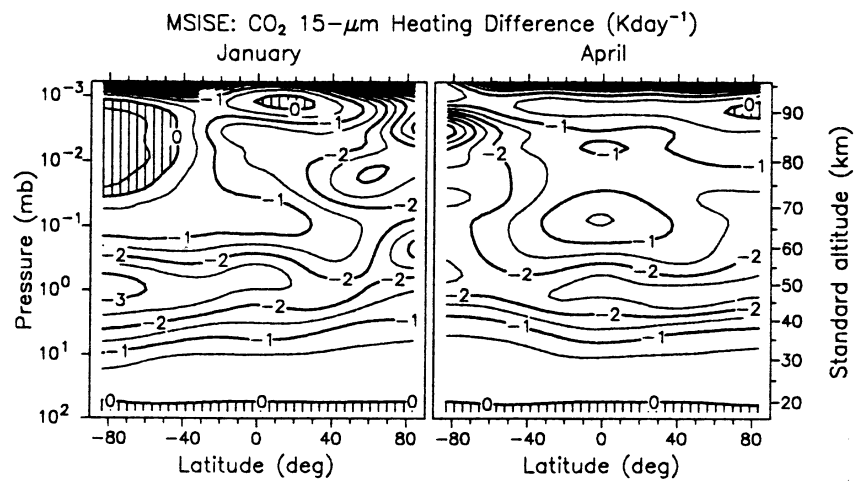

Fig. 3. Heating rate difference $\left(2 \times \mathrm{CO}_{2}-\mathrm{Control}\right)$ in the $15-\mu \mathrm{m} \mathrm{CO}$ band due to doubling of $\mathrm{CO}_{2}$ in a standard atmosphere below about $95 \mathrm{~km}$ (positive area shaded, contour interval $0.5 \mathrm{~K} \mathrm{day}^{-1}$ )

results do not show a sharp maximum in the $\mathrm{CO}_{2}$ forcing around $100 \mathrm{~km}$ as in the work by Berger and Dameris (1993) (compare our Fig. 4 with their Fig. 5). Instead, the forcing maximizes at about $120 \mathrm{~km}$ and is much stronger in the thermosphere. In the lower thermosphere, the atmosphere becomes transparent in the $15-\mu \mathrm{m}$ band and the heating rate is roughly proportional to $c_{\mathrm{CO}_{2}}$ at a given height. Therefore the radiative drive due to doubling of $\mathrm{CO}_{2}$ here almost 


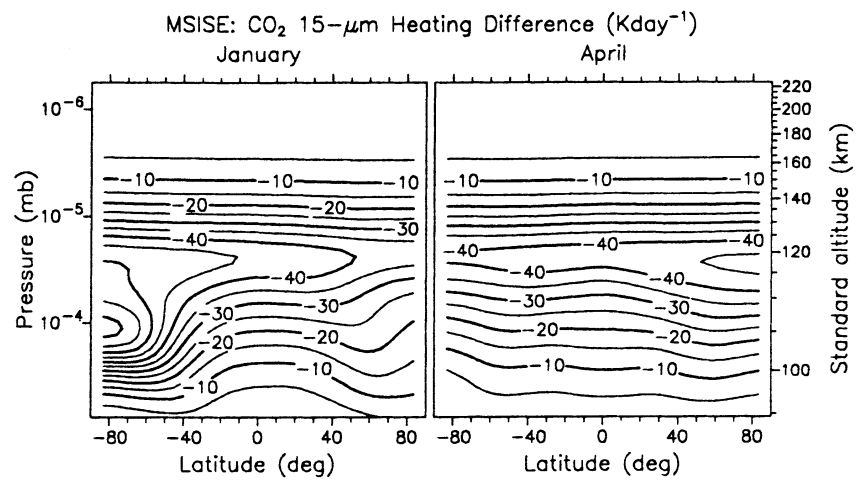

Fig. 4. Same as in Fig. 3 but above $95 \mathrm{~km}$ (contour interval $5 \mathrm{~K} \mathrm{day}^{-1}$ )

equals the heating rate for standard conditions (compare Figs. 2 and 4). Also note that the heating rate itself and radiative forcing are positive around the summer mesopause at high-latitudes (Figs. 1 and 3) due to the heat exchange of this cold region with relatively warm layers below (cf, Berger and Dameris, 1993; Portmann et al., 1995). Otherwise the initial radiative forcing is negative almost everywhere in the MLT and it tends to cool the atmosphere.

The infrared heating rates usually strongly depend on atmospheric temperature. If there were no other processes with temperature-dependent energy output, the thermal response would generally follow the pattern presented in Figs. 3 and 4. The atmosphere would cool or warm in the areas with negative and positive forcing, respectively, until the forcing is entirely compensated by changes in the temperature distribution and a new quasi-equilibrium balance is reached. As the atmosphere cools, however, various physical processes may be able to shift the energy balance and compensate part of the initial forcing. Some of these dynamical and chemical feedbacks have already been briefly discussed in previous sections. Figure 5 presents the $15-\mu \mathrm{m}$ heating rate differences between the simulations with $2 \times \mathrm{CO}_{2}$ and control simulations above $95 \mathrm{~km}$. It can be seen from comparison with Fig. 4 that the initial radiative forcing is almost exactly compensated by temperature changes approximately below the pressure level of $10^{-4} \mathrm{mb}$ (standard height about $110 \mathrm{~km}$ ). Above this level, the residual radiative cooling is compensated primarily by enhanced molecular thermal conductivity. Some consequences of this for the vertical temperature distribution in the thermosphere are discussed in the next section and in the Appendix.

Another example of feedbacks is presented in Figs. 6 and 7 for the region around the stratopause. The role of the radiative heating in the 9.6- $\mu \mathrm{m}$ band of ozone was discussed by Fels et al. (1980) in conjunction with their experiments with a $50 \%$ reduction of $\mathrm{O}_{3}$. In particular, it was noted that this mechanism could provide a positive radiative drive maximizing at about $0.4 \mathrm{~K}$ day $^{-1}$ at the stratopause in addition to the negative forcing due to absorption of solar radiation. A net residual heating of the same magnitude is generated for a fixed ozone distribution in response to temperature changes driven by doubling of $\mathrm{CO}_{2}$. Interestingly, this net heating almost exactly compensates the residual cooling in the $15-\mu \mathrm{m}$ band. The radiative feedback due to heating in the 9.6- $\mu \mathrm{m}$ ozone band represents an additional mechanism for damping the thermal response in the upper stratosphere and lower mesosphere. In fact, this feedback must be even stronger if the ozone concentration increases in a colder stratosphere. This additional effect due to increased ozone concentration

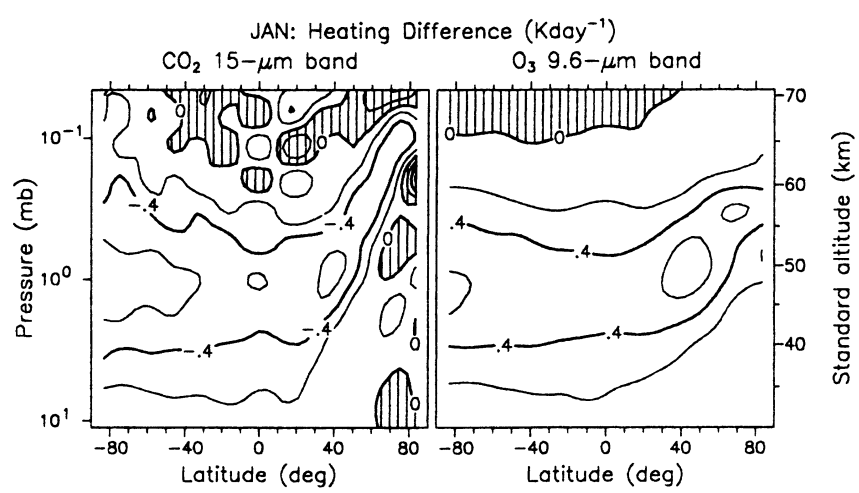

Fig. 6. Heating rate difference $\left(2 \times \mathrm{CO}_{2}-\mathrm{Control}\right)$ for quasistationary conditions in January (contour interval $0.2 \mathrm{Kday}^{-1}$ ): $15-\mu \mathrm{m} \mathrm{CO}_{2}$ band (left panel, positive area shaded); 9.6- $\mu \mathrm{m} \mathrm{O}_{3}$ band (right panel, negative area shaded)

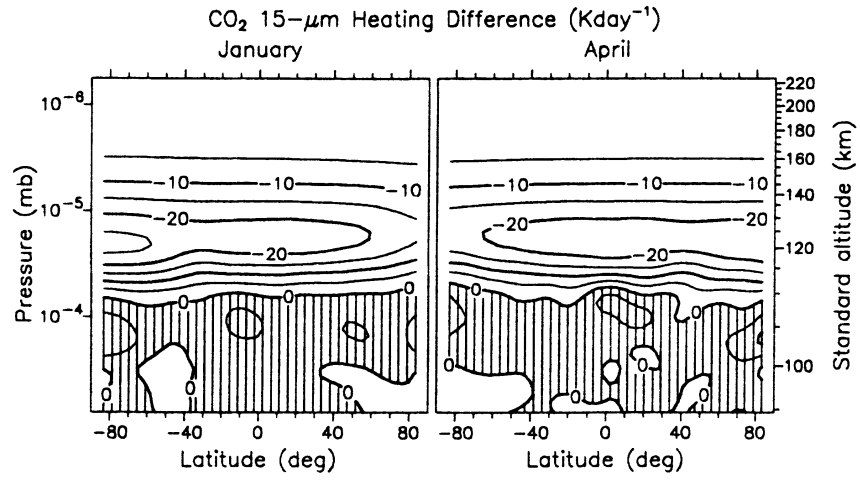

Fig. 5. Same as in Fig. 4 but for quasi-stationary conditions after integration of the model for 1 year

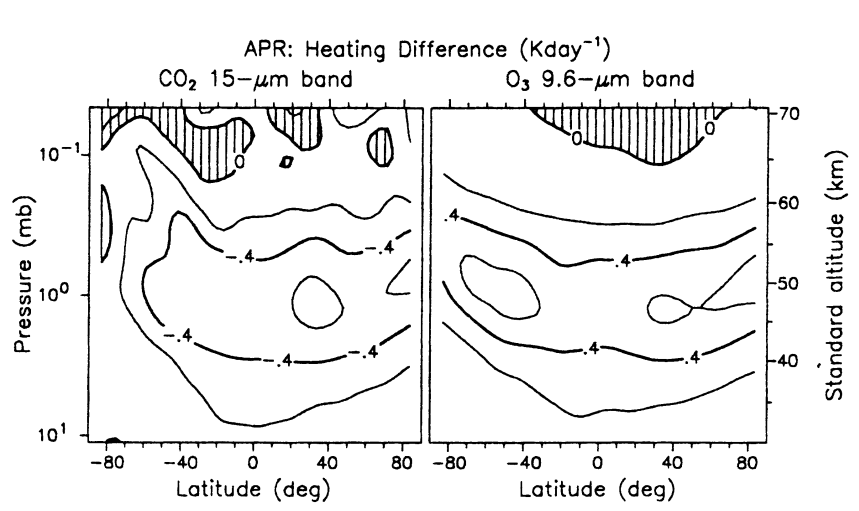

Fig. 7. Same as in Fig. 6 but for April 
can only be simulated by a model with interactive composition and chemistry and was not accounted for by Fels et al. (1980).

\section{Atmospheric response}

Figures 8 and 9 present zonal mean temperature differences $\Delta T$ for quasi-equilibrium conditions in the whole model domain as a function of pressure. Note that, as in all previous figures, the "standard height" corresponds to the control case. Due to a substantial cooling in the middle and upper atmosphere, the pressure levels with $2 \times \mathrm{CO}_{2}$ shift downward and the effect increases with height. Some consequences of this thermal shrinking of the atmosphere are discussed in more detail later. The average cooling at the stratopause (Fig. 8) is about $14 \mathrm{~K}$ in good agreement with other simulations without chemical feedbacks due to ozone chemistry in the stratosphere (e.g., Berger and Dameris, 1993). The temperature difference gradually decreases in the mesosphere to about $-8 \mathrm{~K}$ around the mesopause comparable with that obtained by Berger and Dameris (1993) and Portmann et al. (1995). Contrary to the results of Rind et al. (1990), there is no positive response in the mesosphere even in the region of the summer mesopause with a positive radiative forcing (Fig. 3).

In the lower thermosphere (Fig. 9), there is little dependence of the thermal response on latitude although the initial radiative forcing has some latitudinal structure, in particular at solstice (Fig. 4). Another notable feature is that the temperature difference continually grows in magnitude into the thermosphere although the initial (Fig. 4) and residual (Fig. 5) radiative forcing in the lower thermosphere decreases above approximately $120 \mathrm{~km}$. As demonstrated in the Appendix, the monotonic increase of thermal response with log-pressure height is characteristic for a thermosphere where the vertical temperature profile is determined by a balance between molecular heat conductivity and radiative (EUV) heating if the latter does not strongly depend on temperature, i.e., if there are no strong feedbacks. The increasing temperature difference (Fig. 9) qualita-

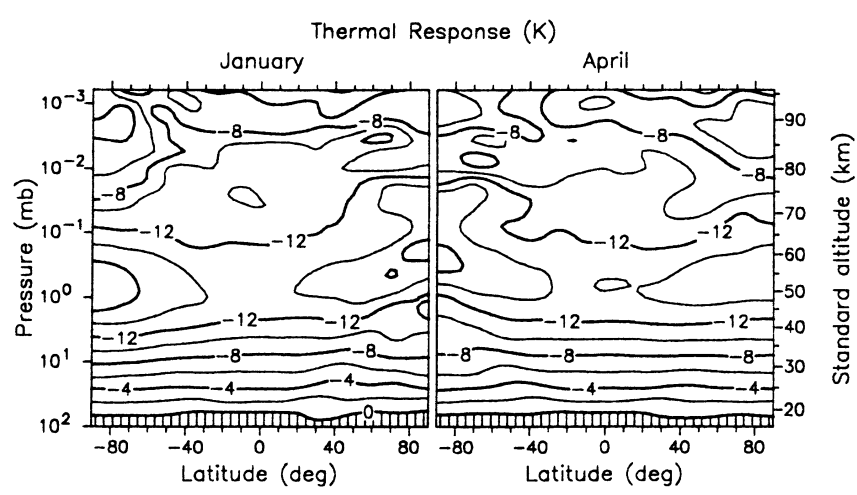

Fig. 8. Temperature difference $\left(2 \times \mathrm{CO}_{2}-\mathrm{Control}\right)$ as a function of pressure for quasi-stationary conditions below $95 \mathrm{~km}$ (positive area shaded, contour interval $2 \mathrm{~K}$ )

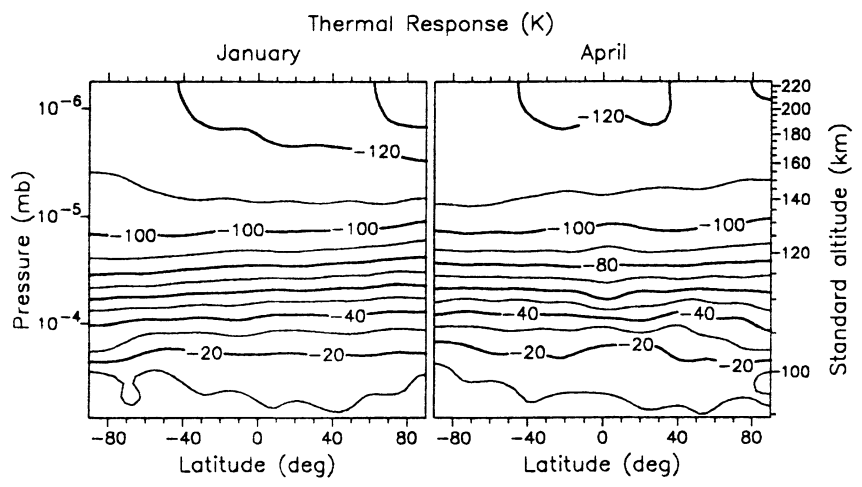

Fig. 9. Same as in Fig. 8. but above $95 \mathrm{~km}$ (contour interval $10 \mathrm{~K}$ )

tively agrees with the simulations by Roble and Dickinson (1989) and Rishbeth and Roble (1992) for low solar activity. One must bear in mind however that in these two papers the results are apparently presented in terms of geometric height. Thermal response at a given height in the upper atmosphere is drastically different from the response at a given pressure level as in Figs. 8 and 9 (see Figs. 11 and 12).

Our simulations in the lower thermosphere differ from the results of Berger and Dameris (1993). They obtained a layer of strong cooling of about $40 \mathrm{~K}$ at $100-105 \mathrm{~km}$ compared to about $20 \mathrm{~K}$ in Fig. 9. This maximum in cooling is apparently associated with the sharp maximum in $\mathrm{CO}_{2}$ radiative forcing at about $100 \mathrm{~km}$ in the study by Berger and Dameris (1993). Our results do not confirm the existence of these maxima in forcing and thermal response although $k_{\mathrm{O}}$ used in the present simulations is more than an order of magnitude greater than used by Berger and Dameris (1993). Higher into thermosphere, $\Delta T$ substantially decreases in magnitude in their study contrary to the results in Fig. 9. This difference may be a combination of two factors. First, the $\mathrm{CO}_{2}$ forcing is very weak above $110-115 \mathrm{~km}$ in the work by Berger and Dameris (1993). Second, the thermal response may be damped by feedbacks due to radiative cooling in the $5.3-\mu \mathrm{m} \mathrm{NO}$ band explicitly treated in their model. It is difficult to estimate which of the two factors is more important. The second effect could be overestimated in simulations by Berger and Dameris (1993) using the same concentration of $\mathrm{NO}$ in control and $2 \times \mathrm{CO}_{2}$ simulations. The simulations of Roble and Dickinson (1989) predict a decrease of the NO concentration by up to $50 \%$ in the lower thermosphere with doubled $\mathrm{CO}_{2}$. Further studies are necessary to improve estimates of thermal response in the lower thermosphere.

As already mentioned, some numerical experiments have been performed with a two-dimensional configuration of the model with no tidal forcing. Otherwise the model parameters have been specified as in the corresponding three-dimensional runs. In particular, daily and zonally averaged solar heating rates from threedimensional experiments have been used. The interaction of GWs with tides is a non-linear process. The presense of tides changes the zonal mean deposition of 
momentum and energy by GWs. It has been found that the thermal response to doubling of $\mathrm{CO}_{2}$ changes too. In particular, there are noticeable differences of about $\pm 5 \mathrm{~K}$ in the thermal response (not shown) around the mesopause at low latitudes where the diurnal tide is strong (e.g., Akmaev et al., 1997). It would be interesting to test if this effect can be reproduced with a different kind of GW parametrization. Incidentally, no substantial changes in tidal amplitudes have been detected with doubled $\mathrm{CO}_{2}$. In principle, the radiative transfer in the $15-\mu \mathrm{m}$ band must act as a tidal dissipative mechanism. However, it does not appear to be a major factor.

Figure 10 compares GW zonal momentum deposition rates for solstice conditions when the net drag is strong. This is another example of interactions of waves with the background atmosphere. The maximum wave drag in the upper mesosphere and just above the mesopause is stronger by up to $20-40 \mathrm{~m} \mathrm{~s}^{-1} \mathrm{day}^{-1}$ with doubled $\mathrm{CO}_{2}$ which is generally consistent with the results of Rind et al. (1990). Note that in the present simulations the intensity of $\mathrm{GW}$ source in the lower atmosphere has not been changed for $2 \times \mathrm{CO}_{2}$ experiments. If the strength of the source increases as suggested by Rind et al (1990), GW drag and energy deposition may increase even further and substantially affect the zonal mean circulation in the MLT.

The relatively strong cooling in the middle and upper atmosphere (Figs. 8 and 9) causes thermal shrinking in an atmosphere with static balance, i.e., a drop in height of any given pressure levels. From the static equation, the relative change in height $\Delta z / z$ is roughly proportional to the relative change of temperature, $\Delta \bar{T} / \bar{T}$, averaged over the log-pressure height. This means that the relative change in height is greater if $|\Delta \bar{T}|$ is greater. This also means that the relative response is stronger in the regions of relatively low temperatures, $\bar{T}$, e.g., for a given $\Delta \bar{T}, \Delta z / z$ must be greater in the upper mesosphere than in the thermosphere. One must keep in mind however that the absolute height change, $\Delta z$, is approximately proportional to $z$, and although relative temperature changes may be smaller in the thermosphere due to higher background temperatures, the effect also

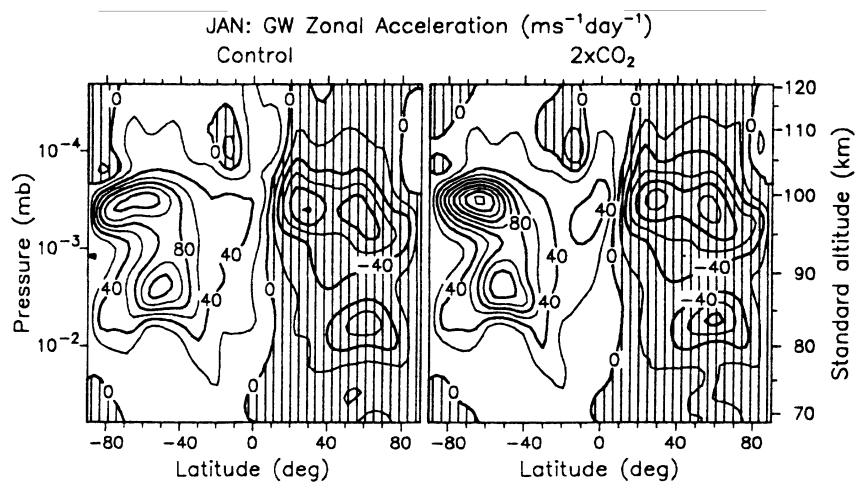

Fig. 10. Zonal mean GW zonal momentum deposition rate for January [contour interval $20 \mathrm{~m} \mathrm{~s}^{-1}$ day $^{-1}$, area of negative (westward) acceleration shaded]: control experiment (left panel); $2 \times \mathrm{CO}_{2}$ (right panel) accumulates with height. In our simulations, for example, the upper boundary dropped by about $30 \mathrm{~km}$ with doubled $\mathrm{CO}_{2}$.

Pressure is commonly used as a vertical coordinate in middle and upper atmospheric models while observations are often related to geometric altitude. It is therefore interesting to see how the temperature differences would look in terms of geometric height. The transformation of $\Delta T$ from log-pressure to geometric height can be more clearly seen on vertical temperature profiles. Figure 11 compares global mean temperature profiles for both seasons as a function of pressure, and Fig. 12 presents the same comparison as a function of geometric height. The transformation from Fig. 11 to Fig. 12 is determined by several factors. One of them is the fact that the vertical displacement $\Delta z$ tends to grow with height. As a result, $\Delta T$ looks quite similar in the lower part of model domain, approximately below the stratopause. The differences then accumulate rapidly with height and maximize in the thermosphere. Another factor worth mentioning here is that the background temperature profile has a negative vertical gradient in the mesosphere and a positive gradient in the thermosphere. Thus the "apparent" $\Delta T$ seen in terms of geometric height is caused by a combination of a

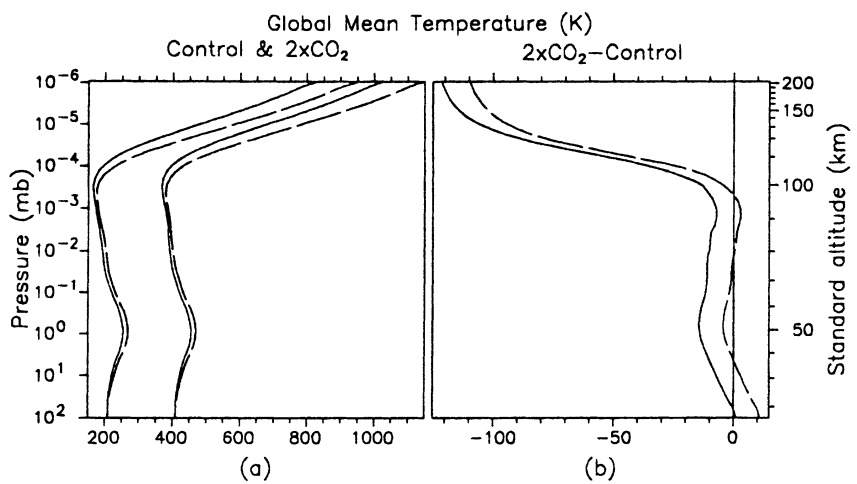

Fig. 11. Global mean temperature as a function of pressure (left panel): control experiments (dashed), $2 \times \mathrm{CO}_{2}$ experiments (solid); January (left curves), April (right curves) shifted by $200 \mathrm{~K}$ ). Global mean temperature difference $\left(2 \times \mathrm{CO}_{2}-\mathrm{Control}\right)$, as a function of pressure (right panel): January (solid), April (dashed, shifted by $10 \mathrm{~K}$ )

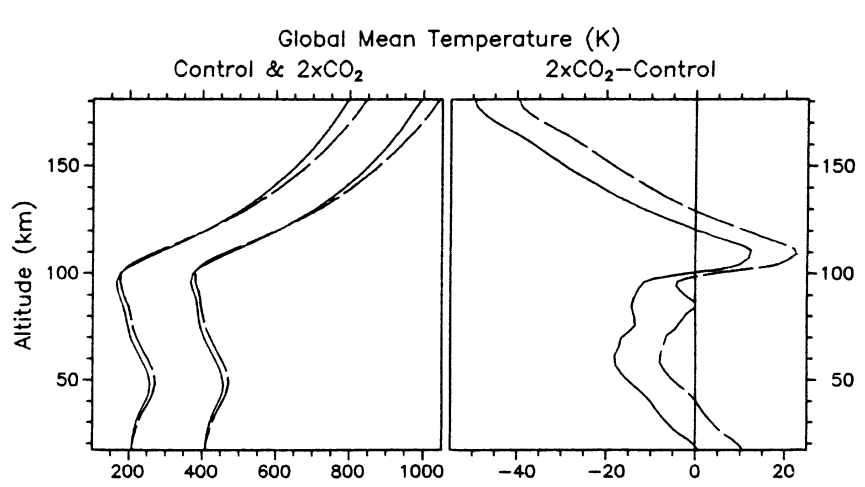

(a)

(b)

Fig. 12. As in Fig. 11 but as a function of geometric height 
cooling at fixed pressure and a descent of air at lower pressure to the given height. In the mesosphere this enhances the apparent cooling. Roughly speaking, the mesopause descends into what used to be the middle and upper mesosphere, etc. A similar mechanism works above the mesopause with the opposite effect since the background temperature profile has a strong positive vertical gradient, particularly in the lower thermosphere. This results in a layer of "apparent heating" of up to about $10 \mathrm{~K}$ at $100-120 \mathrm{~km}$. The maximum average cooling in the lower thermosphere is now only about 40 $50 \mathrm{~K}$ (Fig. 12) compared to $110-120 \mathrm{~K}$ in Fig. 11. These results qualitatively agree with simulations by Rishbeth and Roble (1992).

According to the ideal gas law, cooling in the middle and upper atmosphere (Figs. 8 and 9) must result in a density increase at a given pressure. However, in combination with the thermal shrinking, atmospheric density at a given height decreases in the MLT (Fig. 13). In the present simulations the density decrease maximizes at about $50 \%$ just above $100 \mathrm{~km}$. Higher in the thermosphere the average density reduction is about 40 $45 \%$ in good agreement with predictions of Roble and Dickinson (1989) and Rishbeth and Roble (1992).

\section{Concluding remarks}

A new parameterization of the $15-\mu \mathrm{m} \mathrm{CO}_{2}$ band has been incorporated into the Spectral mesosphere/lower thermosphere model. The parametrization is applicable to calculations of radiative heating rates above approximately $15 \mathrm{~km}$ for arbitrary vertical profiles of the $\mathrm{CO}_{2}$ concentration corresponding to the surface mixing ratio in the range $150-720 \mathrm{ppm}$. Numerical experiments have been conducted to estimate the sensitivity to doubling of $\mathrm{CO}_{2}$ in the MLT. The thermal response in the MLT is much stronger than in the lower atmosphere and mostly negative (cooling). An average cooling at the stratopause is about $14 \mathrm{~K}$. It gradually decreases to approximately $8 \mathrm{~K}$ in the upper mesosphere. This is in reasonable agreement with other studies. In the thermosphere the cooling increases up to $40-50 \mathrm{~K}$ at a given

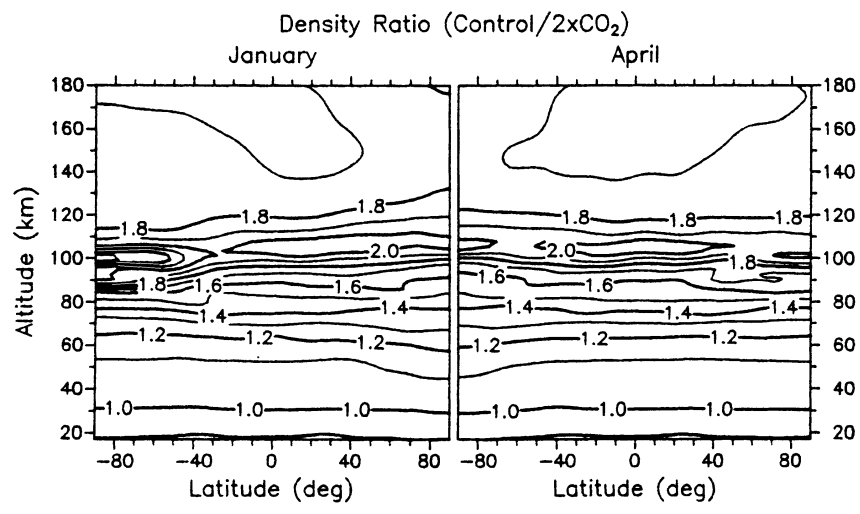

Fig. 13. Density ratio (Control $\left./ 2 \times \mathrm{CO}_{2}\right)$ as a function of geometric height (contour interval 0.1): January (left panel); April (right panel) height. It is noted that although temperatures decrease at any pressure level in the MLT, the thermal shrinking of the atmosphere may lead to apparent heating at a given height, in particular in the lower thermosphere.

Various possible radiative, chemical, and dynamical feedbacks important for simulations of the $2 \times \mathrm{CO}_{2}$ climate in the MLT are discussed. There is no ideal numerical model that could account for all potentially important processes including the influence of lower atmospheric forcing and "in situ" feedbacks. Some of these feedbacks are not represented in the current configuration of the model. Therefore the present results can only be considered first crude estimates. It is important for future work to identify potentially important mechanisms and incorporate them into simulations in a self-consistent way. For example, cooling at the stratopause and in the lower mesosphere may be overestimated by about $3 \mathrm{~K}$ due to neglect of the ozone chemistry (cf Fels et al., 1980). Some of the feedbacks are already incorporated into the SMLTM, e.g., those due to infrared radiation in the $9.6-\mu \mathrm{m}$ band of ozone, propagation and breaking of gravity waves.

The effects of strong tides on thermal response in the MLT have been studied for the first time. It has been found that the presence of tides can noticeably $( \pm 5 \mathrm{~K})$ modify the atmospheric response in the vicinity of mesopause. It would be interesting to investigate if this effect could be reproduced with a different GW parametrization scheme.

It is shown that the thermal response is a monotonically increasing function of log-pressure height in a thermosphere without strong thermal feedbacks. The effect may be reversed, for example, in layers with strong temperature-sensitive emissions, e.g., in the $5.3-\mu \mathrm{m}$ NO band at $140-150 \mathrm{~km}$. The role of this emission must be studied further in a self-consistent way to simultaneously account for possible changes in temperature and concentration of NO.

The overall cooling and associated thermal shrinking result in a substantial density reduction in the MLT (Fig. 13). The density decrease reaches $40-45 \%$ in the thermosphere with a maximum of about $50 \%$ just above $100 \mathrm{~km}$.

The amount of $\mathrm{CO}_{2}$ in the atmosphere has "only" increased by about $12 \%$ during the last 30 years (e.g., Kane and de Paula, 1996). It would therefore be inappropriate to directly compare simulations of atmospheric response to doubling of $\mathrm{CO}_{2}$ with long-term observations in the MLT. Although inconclusive, the available observations reveal some features that are strikingly similar to the simulations. These include the overall cooling trend in the MLT maximizing in the upper mesosphere, no apparent cooling around $100 \mathrm{~km}$, a comparatively strong cooling higher in the thermosphere (e.g., compare Fig. 12 in this work with Fig. 3 in the paper by Semenov, 1996), and a substantial descent of ionospheric and emission layers in the thermosphere. These similarities suggest that during the last 3-4 decades real changes have occurred in the middle and upper atmosphere comparable in strength to the impact of doubling of $\mathrm{CO}_{2}$. 


\section{Appendix}

Consider changes in an equilibrium temperature profile caused by cooling or heating in the thermosphere. The "thermosphere" is assumed to be a region where the vertical temperature profile is primarily determined by the balance between molecular heat conduction and "radiative" heating. Horizontal heat transport and diurnal variations of the heating are neglected so that the following is meant to be applicable, for example, to a globally and daily averaged temperature profile. The problem can be formalized as follows. Find solution of the energy balance equation:

$\frac{1}{\rho c_{p}} \frac{\mathrm{d} F}{\mathrm{~d} z}=h$

where $z$ is height, $\rho$ atmospheric density, $c_{p}$ specific heat at constant pressure, $h$ heating rate per unit mass. The molecular heat flux, $F$, is proportional to the vertical temperature gradient:

$F=-\lambda \frac{\mathrm{d} T}{\mathrm{~d} z}$

where $\lambda$ is molecular thermal conductivity. Let us rewrite Eq. (A1) in terms of log-pressure height, $x=\ln \left(p_{0} / p\right)$, where $p_{0}$ is some reference pressure:

$-\frac{g}{c_{p} p} \frac{\mathrm{d}}{\mathrm{d} x}\left(\frac{g \mu}{R} \frac{\lambda}{T} \gamma\right)=h$

where $R$ is the gas constant, $g$ gravity acceleration, $\mu$ molecular mass, and $\gamma=\mathrm{d} T / \mathrm{d} x$. Assume that composition depends only on pressure, i.e., if there is thermal shrinking or expansion of the atmosphere, the composition "follows" pressure levels (see Rishbeth, 1990). This means that $\mu$ and $c_{p}$ only depend on $x$, not $T$. Changes in $g$ due to possible shrinking or expansion are also neglected, i.e., $g$ is also a function of $x$ only. Finally, for the coefficient of molecular thermal conduction we assume that $\lambda=\lambda_{0} T^{a}$ where $\lambda_{0}$ depends only on composition and thus on $x$ (Banks and Kockarts, 1973).

First, consider the case where $h$ only depends on the composition at a given pressure level, not on temperature, as is typical for direct solar EUV heating for example. Then Eq. (A3) can be written in the following form:

$A(x) \frac{\mathrm{d}}{\mathrm{d} x} F=h(x)$

and the heat flux has the form:

$F=-B(x) T^{a-1} \gamma$

where $A>0$ and $B>0$ depend only on $x$. To find an equilibrium temperature profile, Eqs. (A4) and (A5) can be integrated with appropriate boundary conditions, say, $F(\infty)=0$ and $T\left(x_{b}\right)=T_{b}$ where $x_{b}$ is the lower boundary of the thermosphere. Note that typically $h(x)>0$ in the thermosphere. Then from Eq. (A4) $F(x)$ is a monotonically increasing function $(F(x) \leq 0)$ and $\gamma(x) \geq 0$ is a monotonically decreasing function $(\gamma(x) \rightarrow 0$ as $x \rightarrow \infty)$.
It is immediately seen from Eqs. (A4) and (A5) that for a given vertical profile of $h(x)$ the flux $F(x)$ does not depend on $T\left(x_{b}\right)$. In other words, if the boundary condition $T\left(x_{b}\right)$ changes, the temperature profile $T(x)$ must change in such a way as to keep $F$ constant at any level $x \geq x_{b}$. Equation (A5) can be easily integrated:

$T(x)= \begin{cases}{\left[\left(T_{b}\right)^{a}+a C(x)\right]^{1 / a}} & \text { if } a \neq 0 \\ T_{b} \exp [C(x)] & \text { otherwise }\end{cases}$

where

$C(x)=-\int_{x_{b}}^{x}[F(x) / B(x)] \mathrm{d} x \geq 0$

is a non-negative monotonically increasing function of $x$. Let $T_{0}(x)$ and $T_{1}(x)$ be two solutions of Eqs. (A4) and (A5) corresponding to two boundary conditions $T_{b 0}>T_{b 1}$. It immediately follows from Eqs. (A6) and (A7) that

$T_{0}(x)>T_{1}(x), \quad$ for all $x \geq x_{b}$.

Since $F(x)$ does not depend on $T_{b}$, it also follows from Eqs. (A5) and (A8) that for all $x \geq x_{b}$

$\gamma_{0}>\gamma_{1} \quad$ if $a \leq 1$

$\gamma_{0} \leq \gamma_{1} \quad$ otherwise.

According to Banks and Kockarts (1973) $a=0.69$ and from the first of Eqs. (A9) it follows that

$\gamma_{0}-\gamma_{1}=\frac{\mathrm{d}}{\mathrm{d} x}\left(T_{0}-T_{1}\right)>0$.

This means that the difference $\left(T_{0}-T_{1}\right)$ is a monotonically increasing function of log-pressure height. In other words, if some part of the thermosphere gets colder for some reason, the temperature profile above that region will adjust in such a way that the temperature difference will grow with (log-pressure) height. This behavior is clearly demonstrated in Fig. 11.

Note that Eq. (A10) also holds if the boundary conditions for Eq. (A5), $T_{t 0}>T_{t 1}$, are specified at the upper boundary, say, $x_{t}=\infty$. Then the solution has the same form as in Eq. (A6) where $T_{b}$ should be replaced by $T_{t}$ and $C(x)$ by

$D(x)=\int_{x}^{\infty}[F(x) / B(x)] \mathrm{d} x \leq 0$.

Let us briefly consider other cases. For $a=1$ the difference $\left(T_{0}-T_{1}\right)$ remains constant: the temperature profile gets shifted to the left but remains "parallel" to itself. If $a>1$, the temperature difference decreases with $x$ but Eq. (A8) is still valid.

This analysis is applicable to the present configuration of the model that does not explicitly account for possible thermal feedbacks in the thermosphere ( $h$ is independent of $T$ ). Typically, the feedbacks due to infrared radiation are negative, i.e., $h$ increases with decreasing $T$ and vice versa. This will damp the effect considered here. Very strong feedbacks (strong dependence of $h$ on $T$ ) may even reverse it. A relatively strong cooling in the 5.3- $\mu \mathrm{m} \mathrm{NO}$ band with a maximum at 
140-150 km may be one of the reasons for a weaker temperature response at these heights in the work by Berger and Dameris (1993). Note that above the layer of maximum NO cooling, the mechanism of thermal response in the thermosphere acts as described here (e.g., Roble and Dickinson, 1989).

Finally, similar considerations regarding the vertical dependence of thermal response in the thermosphere are applicable, for example, to comparisons of temperature profiles $T(x)$ obtained for high and low solar activity, i.e., if $h(x)$ increases or decreases in Eq. (A1) but still does not strongly depend on $T$ (e.g., Roble et al., 1987).

Acknowledgements. G. M. Shved initiated this work, his input and stimulating discussions are greatly appreciated. We also thank A. D. Richmond and the referee for helpful comments. This work was supported in part by the Russian Foundation for Basic Research (grants 95-05-14743 and 96-05-64434). RAA also acknowledges support by the US National Science Foundation (NSF) (grants ATM-9523951 and ATM-9714667) and Air Force Phillips Laboratory (contract F196828-96-C-0019). VIF acknowledges support by the Canadian MAM project through grants from the Natural Sciences and Engineering Research Council and the Atmospheric Environment Service. Computing resources were provided by the National Center for Atmospheric Research sponsored by NSF.

Topical Editor F. Vial thanks a referee for the help in evaluating this paper.

\section{References}

Aikin, A. C., M. L. Chanin, J. Nash, and D. J. Kendig, Temperature trends in the lower mesosphere, Geophys. Res. Lett., 18, 461419, 1991.

Akmaev, R. A., Diagnostics and simulation of an annual cycle in the middle atmosphere, J. Geophys. Res., 99, 18933-18950, 1994.

Akmaev, R. A., Optimization of a middle atmosphere diagnostic scheme, J. Atmos. Sol.-Terr. Phys., 59, 983-992, 1997.

Akmaev, R. A., and V. I. Fomichev, Adaptation of a matrix parametrization of the middle atmospheric radiative cooling for an arbitrary vertical coordinate grid, J. Atmos. Terr. Phys., 54, 829-833, 1992.

Akmaev, R. A., V. I. Fomichev, N. M. Gavrilov, and G. M. Shved, Simulation of the zonal mean climatology of the middle atmosphere with a three-dimensional spectral model for solstice and equinox conditions, J. Atmos. Terr. Phys., 54, 119-128, 1992.

Akmaev, R. A., J. M. Forbes, and M. E. Hagan, Simulation of tides with a spectral mesosphere/lower thermosphere model, Geophys. Res. Lett., 23, 2173-2176, 1996.

Akmaev, R. A., V. A. Yudin, and D. A. Ortland, SMLTM simulations of the diurnal tide: Comparison with UARS observations, Ann. Geophysicae, 15, 1187-1197, 1997.

Angell, J. K., Stratospheric temperature change as a function of height and sunspot number during 1972-89 based on rocketsonde and radiosonde data. J. Clim., 4, 1170-1180, 1991.

Banks, P. M., and G. Kockarts. Aeronomy, Part B, Academic Press, New York, 355 pp., 1973.

Berger, U., and M. Dameris. Cooling of the upper atmosphere due to $\mathrm{CO}_{2}$ increases: a model study, Ann. Geophysicae, 11, 809-819, 1993.

Boville, B. A., Detecting $\mathrm{CO}_{2}$-induced temperature changes in the stratosphere, Adv. Space Res., 6, (10)45-(10)48, 1986.

Bremer, J., Ionospheric effects in mid-latitudes as a possible indicator of the atmospheric greenhouse effect, J. Atmos. Terr. Phys., 54, 1505-1511, 1992.
Clemesha, B. R., D. M. Simonich, and P. P. Batista, A long-term trend in the height of the atmospheric sodium layer: possible evidence for global change, Geophys. Res. Lett., 19, 457-460, 1992.

Fels, S. B., J. D. Mahilman, M. D. Schwarzkopf, and R. W. Sinclair, Stratospheric sensitivity to perturbations in ozone and carbon dioxide: radiative and dynamical response. J. Atmos. Sci., 37, 2265-2297, 1980.

Fomichev, V. I., and G. M. Shved, Parametrization of the radiative flux divergence in the $9.6 \mu \mathrm{m} \mathrm{O}_{3}$ band, J. Atmos. Terr. Phys., 47, 1037-1049, 1985.

Fomichev, V. I., and G. M. Shved, Net radiative heating in the middle atmosphere, J. Atmos. Terr. Phys., 50, 671-688, 1988.

Fomichev, V. I., A. A. Kutepov, R. A. Akmaev, and G. M. Shved, Parameterization of the $15 \mu \mathrm{m} \mathrm{CO}_{2}$ band cooling in the middle atmosphere (15-115 km), J. Atmos. Terr. Phys., 55, 7-18, 1993.

Fomichev, V. I., J.-P. Blanchet, and D. S. Turner, Matrix parameterization of the $15 \mu \mathrm{m} \mathrm{CO}_{2}$ band cooling in the middle and upper atmosphere for arbitrary $\mathrm{CO}_{2}$ concentration, $J$. Geophys. Res., 103, in press, 1988.

Gadsden, M., A secular change in noctilucent cloud occurrence, $J$. Atmos. Terr. Phys., 52, 247-251, 1990.

Gates, W. L., J. F. B. Mitchell, G. J. Boer, U. Cubasch, V. P. Meleshko, Climate modelling, climate prediction and model validation, in Climate Change 1992, Eds. J. T. Houghton, B. A. Callander and S. K. Varney, Cambridge University Press, 97133, 1992.

Gavrilov, N. M., Parametrization of accelerations and heat flux divergences produced by internal gravity waves in the middle atmosphere, J. Atmos. Terr. Res., 52, 707-713, 1990.

Golitsyn, G. S., A. I. Semenov, N. N. Shefov, L. M. Fishkova, E. V. Lysenko, and S. P. Perov, Long-term temperature trends in the middle and upper atmosphere, Geophys. Res. Lett., 23, 17411744, 1996.

Hagan, M. E., J. M. Forbes, and F. Vial, On modeling migrating solar tides, Geophys. Res. Lett., 22, 893-896, 1995.

Hauchecorne, A., M.-L. Chanin, and P. Keckhut, Climatology and trends of the middle atmospheric temperature $(33-87 \mathrm{~km})$ as seen by Rayleigh lidar over the south of France, J. Geophys. Res., 96, 15297-15309, 1991.

Hedin, A. E., Extension of the MSIS thermosphere model into the middle and lower atmosphere, J. Geophys. Res., 96, 1159-1172, 1991.

Kane, R. P., and E. R. de Paula, Atmospheric $\mathrm{CO}_{2}$ changes at Mauna Los, Hawaii, J. Atmos. Terr. Phys., 58, 1673-1681, 1996.

Kockarts, G., Nitric oxide cooling in the terrestrial thermosphere, Geophys. Res. Lett., 7, 137-140, 1980.

Kokin, G. A., and E. V. Lysenko, On temperature trends of the atmosphere from rocket and radiosonde data, J. Atmos. Terr. Phys., 56, 1035-1040, 1994.

Lindzen, R. S., Turbulence and stress owing to gravity wave and tidal breakdown, J. Geophys. Res., 86, 9707-9714, 1981.

Mlynczak, M. G., and S. Solomon, A detailed evaluation of the heating efficiency in the middle atmosphere, J. Geophys. Res., 98, 10517-10541, 1993.

Portmann, R. W., G. E. Thomas, S. Solomon, and R. R. Garcia, The importance of dynamical feedbacks on doubled $\mathrm{CO}_{2}$-induced changes in the thermal structure of the mesosphere, Geophys. Res. Lett., 22, 1733-1736, 1995.

Riese, M., D. Offermann, and G. Brasseur, Energy released by recombination of atomic oxygen and related species at mesopause heights, J. Geophys. Res., 99, 14585-14593, 1994.

Rind, D., R. Suozzo, N. K. Balachandran, and M. J. Prather, Climate change in the middle atmosphere. Part I: the doubled $\mathrm{CO}_{2}$ climate, J. Atmos. Sci., 47, 475-495, 1990.

Rishbeth, H., A greenhouse effect in the ionosphere? Planet. Space, Sci., 38, 945-948, 1990.

Rishbeth, H., and R. G. Roble, Cooling of the upper atmosphere by enhanced greenhouse gases - Modelling of thermospheric and ionospheric effects, Planet. Space Sci., 40, 1011-1026, 1992. 
Roble, R. G., Energetics of the mesosphere and thermosphere, in The upper mesosphere and lower thermosphere: a review of experiment and theory, Eds. R. M. Johnson and T. L. Killeen, AGU, Washington, DC, 1-21, 1995.

Roble, R. G., and R. E. Dickinson, How will changes in carbon dioxide and methane modify the mean structure of the mesosphere and thermosphere? Geophys. Res. Lett., 16, 14411444, 1989.

Roble, R. G., E. C. Ridley, and R. E. Dickinson, On the global mean structure of the thermosphere, J. Geophys. Res., 92, 8745-8758, 1987.

Semenov, A. I., Temperature regime of the lower thermosphere from emission measurements during the last decades, Geomagn. Aeronomy, 36, (5)90-(5)97, 1996.

Shved, G. M., L. E. Khvorostovskaya, I. Yu. Potekhin, A. I. Demianikov, A. A. Kutepov, and V. I. Fomichev, Measurement of the quenching rate constant for collisions $\mathrm{CO}_{2}\left(01^{1} 0\right)-\mathrm{O}$ : The importance of the rate constant for the thermal regime and radiation in the lower thermosphere, Atmos. Ocean. Phys., 27, 431-437, 1991.

Shved, G. M., A. A. Kutepov, and V. P. Ogibalov, Non-local thermodynamic equilibrium in $\mathrm{CO}_{2}$ in the middle atmosphere. I. Input data and populations of the $v_{3}$ mode manifold states, $J$. Atmos. Sol.-Terr. Phys., 60, 289-314, 1998.

Taubenheim, J., G. von Gossart, and G. Entzian, Evidence of $\mathrm{CO}_{2}-$ induced progressive cooling of the middle atmosphere derived from radio observations, Adv. Space Res., 10, (10)171-(10)174, 1990.

Tobiska, W. K., Revised solar extreme ultraviolet flux model, $J$. Atmos. Terr. Phys., 53, 1005-1018, 1991.

Ulich, T., and E. Turunen, Evidence for long-term cooling of the upper atmosphere in ionosonde data, Geophys. Res. Lett., 24, 1103-1106, 1997. 